\title{
Psicooncología
}

ISSN: 1696-7240

https://dx.doi.org/10.5209/psic.77752

\section{Efficacy of Meaning-Centered Psychotherapy in adult patients with advanced cancer: A systematic review and meta-analysis}

\author{
Natalia Dietrich ${ }^{1 *}$; Andrés Estradé2 $;$ Juan Antonio Cruzado ${ }^{3}$
}

Enviado: 10 de agosto de 2021 / Aceptado: 30 de agosto de 2021

\begin{abstract}
Objective: We conducted a PRISMA-compliant systematic review of clinical trials, and a meta-analysis of randomised clinical trials (RCTs) of manualised Meaning-Centered Psychotherapy (MCP) interventions for adult advanced cancer patients. We searched seven databases for trials published in English and Spanish, until March 27, 2021. Results: Seven trials were included in the systematic review, and four in the meta-analysis. The systematic review favoured the effectiveness of MCP for the improvement of spiritual well-being, quality of life $(\mathrm{QoL})$, sense of meaning and psychological distress, although inconsistencies between the trials were found. In pre-post meta-analytic estimates, MCP had a superior therapeutic effect than control conditions for spiritual well-being $(\mathrm{d}=0.52, \mathrm{p}<0.001)$, QoL $(\mathrm{d}=0.60, \mathrm{p}<0.001)$, anxiety symptoms $(\mathrm{d}=-0.47, \mathrm{p}<0.001)$, depressive symptoms $(\mathrm{d}=-0.50, \mathrm{p}<0.001)$ and desire for hastened death $(\mathrm{d}=-0.28, \mathrm{p}<0.001)$. No differences were observed in between-group comparisons. MCP was not associated with an increased risk of abandonment at post-treatment $(\mathrm{OR}=0.86, \mathrm{p}=0.57)$. Conclusion: Manualised $\mathrm{MCP}$ interventions are a promising treatment for the improvement of spiritual well-being and quality of life and the reduction of psychological distress in adult patients with advanced cancer. The evidence base is still in an emerging state and should be expanded by higher methodological quality studies.
\end{abstract}

Keywords: Meaning-Centered Psychotherapy, advanced cancer, spiritual well-being, psychological distress

\section{[es] Eficacia de la Psicoterapia Centrada en el Sentido en pacientes adultos con cáncer avanzado: revisión sistemática y meta-análisis}

Resumen. Objetivo: se realizó una revisión sistemática de ensayos clínicos siguiendo los criterios PRISMA, y un meta-análisis de ensayos clínicos aleatorizados (ECA), sobre la efectividad de las intervenciones manualizadas de Psicoterapia Centrada en el Sentido (PCS) para pacientes adultos con cáncer avanzado. Se realizaron búsquedas en siete bases de datos de ensayos publicados en inglés y español, hasta el 27 de marzo de 2021. Resultados: siete artículos fueron incluidos en la revisión sistemática y cuatro en el meta-análisis. La revisión sistemática favorece la efectividad de la PCS para mejorar el bienestar espiritual, la calidad de vida, y la experiencia de sentido, así como disminuir el malestar emocional, aunque se encontraron inconsistencias entre los estudios. En los análisis meta-

1 Natalia Dietrich. Universidad Complutense de Madrid, Campus de Somosaguas, Spain.

E-mail: ndietric@ucm.es

2 Andrés Estradé. Early Psychosis: Interventions and Clinical-detection (EPIC) Lab, Department of Psychosis Studies, Institute of Psychiatry, Psychology \& Neuroscience, King’s College London, London, UK.

E-mail: andres.estrade_vaz@kcl.ac.uk

3 Juan Antonio Cruzado. Universidad Complutense de Madrid, Campus de Somosaguas, Spain.

E-mail: jacruzad@ucm.es

* Dirección de correspondencia: Natalia Dietrich. Universidad Complutense de Madrid, Campus de Somosaguas, Spain. E-mail: ndietric@ucm.es 
analíticos pre-post, la PCS tuvo un efecto terapéutico superior a la condición control para bienestar espiritual $(\mathrm{d}=0,52, \mathrm{p}<0,001)$, calidad de vida $(\mathrm{d}=0,60, \mathrm{p}<0,001)$, sintomatología ansiosa $(\mathrm{d}=-0,47$, $\mathrm{p}<0,001)$ y depresiva $(\mathrm{d}=-0,50, \mathrm{p}<0,001)$, y deseos de muerte acelerada $(\mathrm{d}=-0,28, \mathrm{p}<0,001)$. No se encontraron diferencias en las comparaciones intergrupo. La PCS no se asoció a un mayor riesgo de abandono en el post-tratamiento ( $\mathrm{OR}=0,86, \mathrm{p}=0,57)$. Conclusión: los programas manualizados de PCS constituyen un tratamiento prometedor para aumentar el bienestar espiritual y calidad de vida, y reducir el malestar emocional, en pacientes con cáncer avanzado. La evidencia se encuentra aún en un estado emergente, y deberá ser complementada con nuevos estudios de mayor calidad metodológica.

Palabras clave: Psicoterapia Centrada en el Sentido, cáncer avanzado, bienestar espiritual, malestar emocional.

Sumario: 1. Introduction 2. Method. 3. Results 4. Discussion 5. Conclusion 7. References

Cómo citar: Dietrich N, Estradé A, Cruzado JA. Efficacy of Meaning-Centered Psychotherapy in adult patients with advanced cancer: Asystematic review and meta-analysis. Psicooncología 2021; 18:227-244, https://dx.doi.org/10.5209/psic.77752

\section{Introduction}

People faced with a diagnosis of advanced or late-stage cancer often experience existential-related distress, including hopelessness, demoralization, o desire for hastened death ${ }^{(1-4)}$. Observational studies have found a prevalence of $13-18 \%$ of demoralization $^{(5)}$, and up to $20.5 \%$ of desire for hastened death ${ }^{(6)}$ during the late life stages of oncological patients. Authors such as David Kissane ${ }^{(7)}$ and William Breitbart ${ }^{(4,8,9)}$ have suggested that these experiences could represent a response to an existential crisis comprising a loss of meaning, values, and purpose in life. Spiritual well-being and, in particular, a heightened sense of meaning have been found to exert a protecting effect against existential-related distress.

Meaning-Centered Psychotherapy (MCP) is an existentially-oriented psychotherapeutic interventions developed by William Breitbart and his team ${ }^{(9)}$. MCP is a brief manualized psychotherapeutic programme aimed at strengthening the sense of meaning and life purpose of advanced cancer patients. The development of MCP involved input from cancer patients and takes its inspiration from the works of Victor Frank $l^{(10)}$, by highlighting the spiritual component of humans experience and the central importance of meaning (meaning of life, will to meaning, and freedom of will). MCP seeks to foster a safe therapeutic environment to enable patients to explore their feeling, to facilitate a deeper understanding of their sources of meaning prior to and following the cancer diagnosis, and to help them enrich their sense of meaning ${ }^{(8)}$.

Originally developed as a group intervention for advanced cancer patients ${ }^{(11)}$, MCP was later adapted to individual ${ }^{(12)}$ and palliative care ${ }^{(13)}$ settings. Group (MCGP) and individual (IMCP) programmes share a similar content structure, differing in the number ( 8 and 7 , respectively) and length of sessions ${ }^{(8)}$. On the other hand, the palliative care variant (MCP-PC) is delivered individually, in a shorter 3-session format, and allows for a greater degree of flexibility in the intervention ${ }^{(8,13)}$. Additional variants of MCP were also developed for various populations and settings, including: grief $^{(14)}$, breast cancer survivors ${ }^{(15)}$, cancer caregivers ${ }^{(16)}$, cancer survivors ${ }^{(17)}$, and adolescents and young adult(18). 
Meta-analytical evidence has supported the effectiveness of existentiallyoriented intervention across a wide range of outcomes, including meaning in life $\mathrm{e}^{(19-}$ ${ }^{21)}$, psychopathology ${ }^{(19-21)}$, spiritual well-being ${ }^{(21)}$, quality of life $(\mathrm{QoL})^{(20,21)}$, physical symptoms $^{(21)}$, social relationships ${ }^{(20)}$, self-efficacy ${ }^{(19,20)}$, and hope/optimism ${ }^{(20)}$. However, previous studies have clustered together MCP alongside other existentialoriented interventions (i. e. Logotherapy, Meaning of Life Intervention, Meaning Making Intervention, Supportive Expressive Group, Experiential Group) in their evidence synthesis ${ }^{(19-21)}$. As a result, the specific contribution of MCP towards these outcomes is not clearly stablished. Other methodological shortcomings of previous meta-analyses include the combination of active (e.g. treatment as usual) and non-active (e.g. waitlist) conditions in the control group ${ }^{(19,21)}$, the combination of populations other than cancer patients (e.g. palliative care nurses, HIV patients, police officers, alcohol abuse, chronic pain patients) ${ }^{(19,20)}$, and the inclusion of both randomised and nonrandomised trials ${ }^{(21)}$.

\section{Methods}

\section{Objectives and outcomes}

This is a systematic review and meta-analysis conducted in accordance with PRISMA guidelines (Appendix aTable 1) ${ }^{(22)}$ to assess the effectiveness of manualised MCP interventions for advance adult cancer patients. The selected primary outcomes are spiritual well-being, quality of life (QoL), and sense of meaning. Secondary outcomes considered for the review include anxiety, depression, hopelessness, demoralization, desire for hastened death, satisfaction with the intervention, and risk of abandonment.

\section{Search strategy and selection criteria}

Two independent researchers (ND and AE) conducted the literature search and study selection process. We searched Psychinfo (any field excluding full text, including: APA Psychinfo ${ }^{\circ}$, MEDLINE $®$, Nursing \& Allied Health Database, and Psychology Database) and Web of Science (topic search, including: Web of Science Core Collection, KCI-Korean Journal Database, MEDLINE®, Russian Science Citation Index, SciELO Citation Index) for peer-reviewed articles published in English or Spanish from database inception to March $27^{\text {th }}, 2021$. Search terms included: (meaning-based* OR MCP OR meaning-centered* OR "meaning-centered therapy" OR "meaning-centered psychotherapy" OR psychotherapy) AND (palliative OR "palliative care" OR end-of-life OR terminal OR cancer OR neoplasm OR "advanced cancer" OR oncology) AND "clinical trial" OR RCT OR "controlled trial" OR trial OR random*). References of selected studies were screened for additional publications, and complementary manual searches were conducted in Google Scholar, Cochrane Library, ClinicalTrials.gov.

Abstracts and titles were first screened, and full-texts were then assessed against the following inclusion criteria for the systematic review: a) randomized clinical trials (RCTs), controlled clinical trials (CCT), or uncontrolled clinical trials; b) 
including at least 10 participants; c) participants were mostly adults (at least $80 \%$ $\geq 18$ years or older); d) at least $80 \%$ of participants had a diagnosis of advanced cancer (any type); e) the intervention consisted of a manualised MCP intervention, in any of its forms (IMCP, MCGP, MCP-PC); f) reporting intragroup or betweengroup outcome data, either at end of treatment or follow-up, for any of the primary or secondary outcomes.

For the meta-analysis component of the study, only sources meeting the following criteria were considered: a) randomized clinical trials (RCTs); b) reporting outcome data, either at end of treatment or follow-up, for any of the primary or secondary outcomes; c) providing quantitative data that allows for a menta-analytical synthesis to be conducted. Only studies using an RCT design were selected for the metaanalytical synthesis as they provide highest-quality clinical data with the lowest risk of bias, among the different clinical trial designs.

Studies meeting any of the following criteria were excluded: i) secondary or nonclinical studies; ii) single-case studies or studies with $\mathrm{n}<10$; iii) intervention is not a manualised version of IMCP, MCGP, or MCP-PC; iv) population other than adult advanced cancer patients; v) non-relevant outcome data.

\section{Data extraction process}

The following information was extracted from each source: a) author and publication year; b) country; c) study design; d) sample characteristics, including: gender and age distribution, number of participants at every time point (including reason for disengagement), cancer diagnosis; e) characteristics of the intervention; f) control condition; g) reported primary and secondary outcomes (and assessment instrument); h) statistical measures of effectiveness for each outcome at every time point. The extracted statistical values included the effect size (ES), confidence interval (CI), and p-value. Raw values for each experimental group were also extracted: mean and standard deviation (SD).

We prioritised intragroup and intergroup standardised mean differences (SMD) as the reported effect size (ES). In our report, a SMD $>0$ indicates a therapeutic improvement for the outcomes of spiritual well-being, quality of life (QoL), and sense of meaning. For anxiety, depression, hopelessness, demoralization, and desire for hastened death, a $\mathrm{SMD}<0$ indicates a therapeutic improvement.

\section{Statistical analysis}

A meta-analysis of both intergroup (MCP vs control) and intragroup (i.e. pre-post for MCP and for control) differences was conducted, each primary or secondary outcome with at least two studies $(\mathrm{k} \geq 2)$, and in each measurement time (i.e. baseline, post-treatment, and follow-up). For the calculation of the ES, the mean and SD for each experimental group were converted to Cohen's $d$, a type of SMD. A Cohen's $d$ of 0.20 to 0.49 was interpreted as representing a 'small' therapeutic effect, 0.50 to 0.79 a 'moderate' effect, and $\geq 0.80$ a 'large' effect ${ }^{(23)}$. Statistical significance was defined at $\mathrm{p}<0.05$, two-tailed. For pre-post estimates, a pre-post correlation of 0.59 was inputted as this data was not provided by the primary trials. This was the median value reported in a meta-analysis of 123 studies and 811 individual correlation ${ }^{(24)}$. 
Between-trial heterogeneity was calculated using the $\mathrm{I}^{2}$ statistic, which represents the percentage of total variance resulting from heterogeneity (i.e. real differences in the studies' ES), rather than chance. An $\mathrm{I}^{2}$ was considered 'low' at 25\%, 'medium' at $50 \%$, and 'high' at $75 \%$, as suggested by Higgins et al. $2003^{(25)}$. Additionally, the following analyses were conducted: a) sensitivity analyses for the overall inter and intragroup ESs of primary outcomes using the 'one study removed' function to test the robustness of estimates; and b) an estimation of the risk of abandonment of MCP vs control condition using Odds Ratio (OR) as the ES, so that an OR $>1$ indicates a higher risk of abandonment for MCP. The limited number of studies $(\mathrm{k}<10)$ did not allow for subgroup, meta-regression, and publication bias analyses to be conducted with enough statistical power to render the analyses reliable and were thus discarded ${ }^{(26)}$.

A random-effects model was used for all the meta-analytic estimates, with the inverse-variance method to assign weights ${ }^{(27)}$. Analyses were performed using Comprehensive Meta-Analysis version 3 (CMA3) for Microsoft Windows.

\section{Quality assessment}

Methodological quality assessment of all studies included in the systematic review was performed using the Clinical Trials Assessment Measure (CTAM) instrument ${ }^{(28)}$. The CTAM was specifically developed for the quality assessment of psychotherapy clinical trials. A total of 15 individual items are scored, across 6 domains: i) sampling; ii) allocation; iii) assessment; iv) control group(s); v) analysis; vi) active treatment. A total score is obtained from the sum of all individual items, in a range from 0 (minimum quality) to 100 (maximum quality).

\section{Results}

A total of 2,696 records were identified, 52 were assessed in full-text, and seven met the inclusion criteria. Five $(71 \%)$ of the included trials were classified as "pilot studies" by their authors ${ }^{(11-13,29,30)}$. A flowchart of the search and selection process according to PRISMA guidelines is exposed in Figure 1. Studies not included in the review are also listed (with reasons for their exclusion) in appendix aTable 2.

\section{Characteristics of included studies}

Of the seven included studies, six were $\operatorname{RCTs}^{(11,12,29-32)}$, and one an uncontrolled trial $^{(13)}$. Two RCTs were conducted in Spain ${ }^{(29,30)}$, and the rest in the United States. A total of $n=830$ participants were included, with a median of $n=90$ (range: 11 to 254). All participants had a diagnosis of advanced cancer patients, and in three studies they were receiving palliative care ${ }^{(13,29,30)}$. A summary of the included studies is presented in Table 1.

All studies delivered a manualised form of MCP, with three studies using MCP$\mathrm{PC}^{(13,29,30)}$, two $\mathrm{MCGP}^{(11,31)}$, and two using $\operatorname{IMCP}^{(12,32)}$. Control conditions varied between studies, and included: supportive group psychotherapy ${ }^{(11,31)}$, standard counselling ${ }^{(29)}$, counselling-based psychotherapy ${ }^{(30)}$, supportive psychotherapy ${ }^{(32)}$, enhanced usual care ${ }^{(32)}$, MCP compassionate palliative care ${ }^{(29)}$, and therapeutic massage $^{(12)}$. One study did not include a control group ${ }^{(13)}$. 
Figure 1. PICOS flow diagram outlining the review process

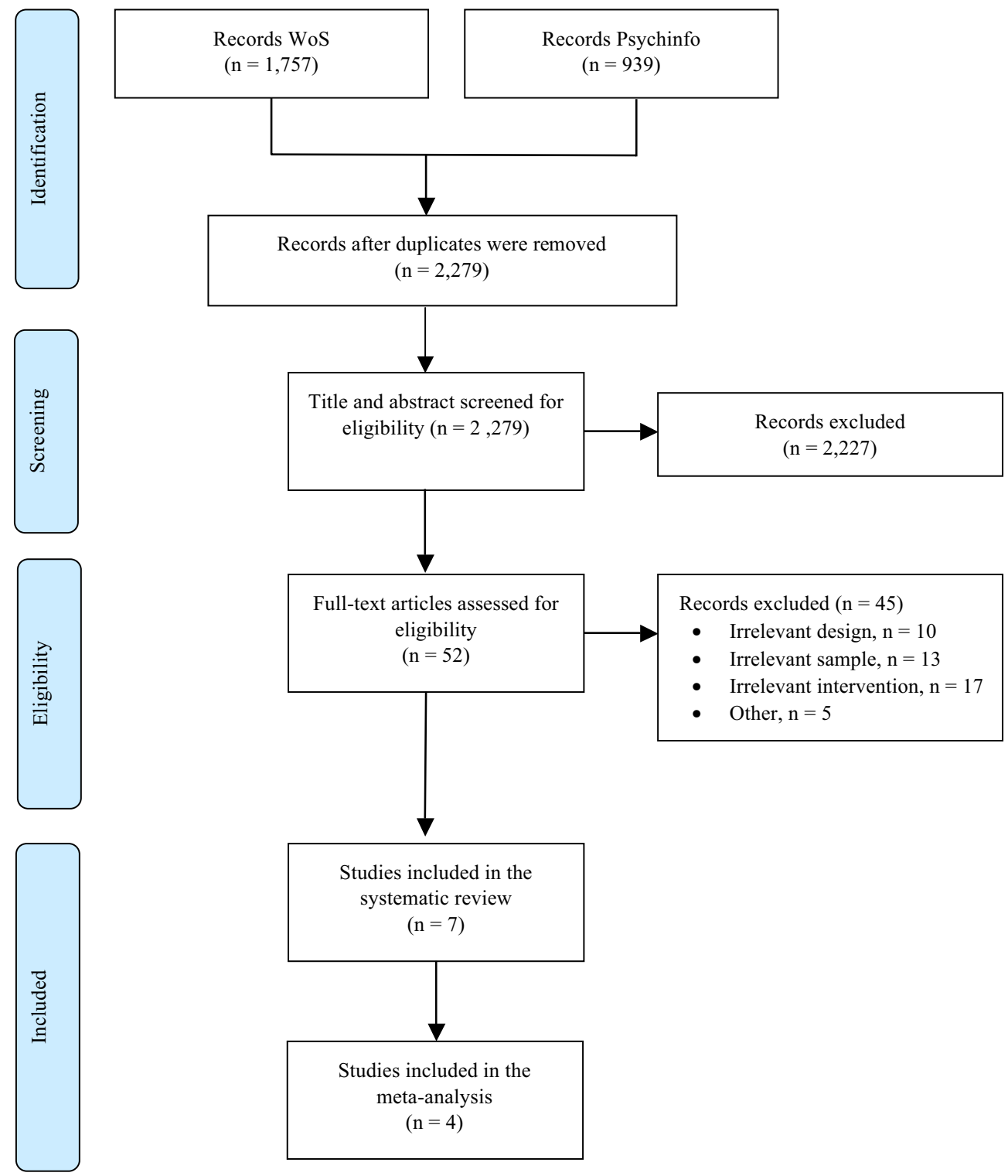




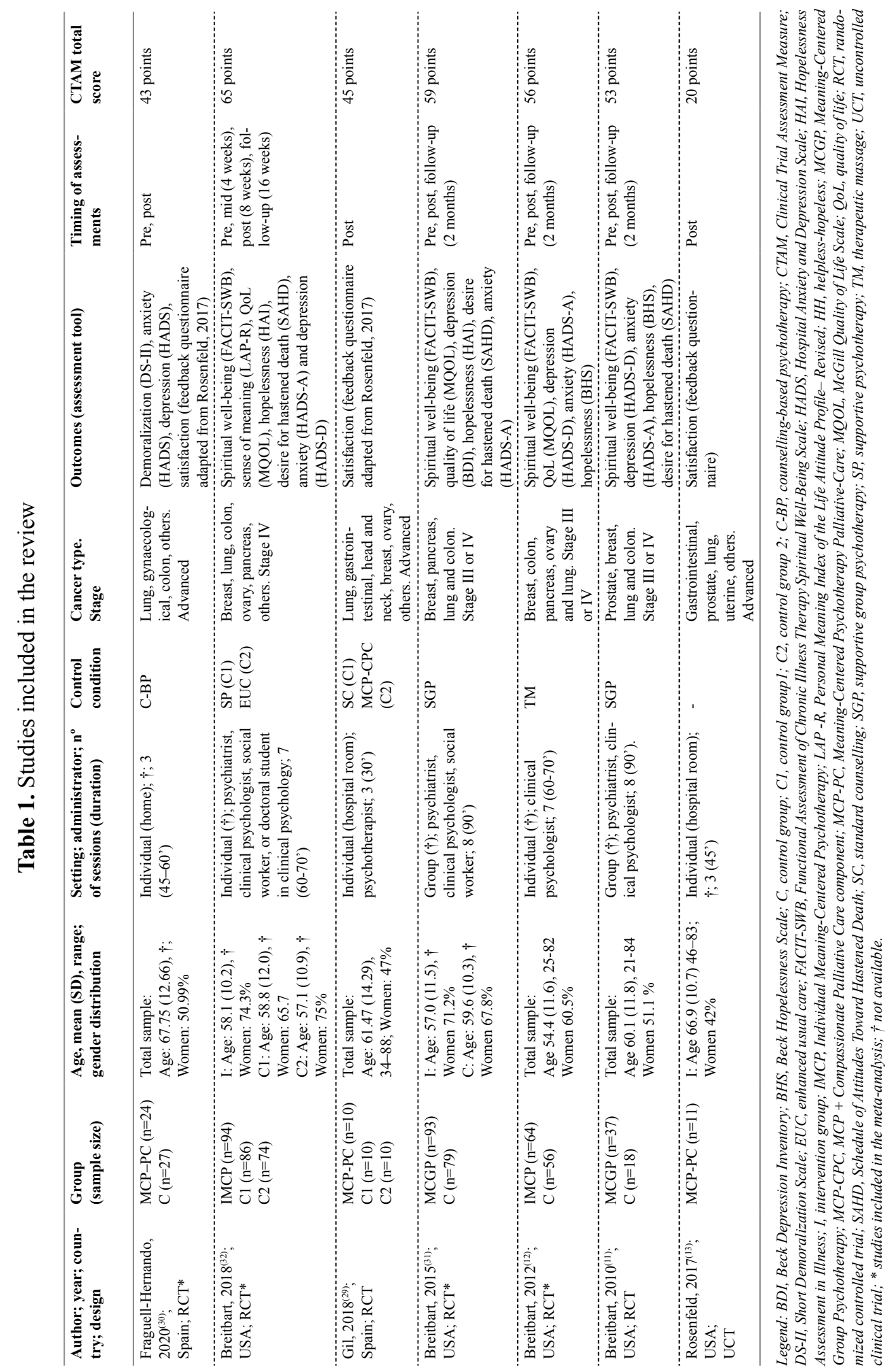




\section{Quality of included studies}

The mean quality score in the CTAM for all studies included in the review was $\mathrm{M}=48.71$ ( $\mathrm{SD}=14.79$ ), with a median of 53 and a range of 20 to 65 . The highestrated study was Breitbart et al. 2018 ${ }^{(32)}$, and the lowest-rated was Rosenfeld et al. $2017^{(13)}$. The mean scores for each CTAM domain were: i) sampling $(\mathrm{M}=2.43$ out of 10 points); ii) allocation ( $\mathrm{M}=3$ out of 16 points); iii) assessment $(\mathrm{M}=1.03$ out of 32 points); iv) control groups ( $\mathrm{M}=9.43$ out of 16 points); $\mathrm{v}$ ) analysis $(\mathrm{M}=5.36$ out of 15 points); vi) active treatment ( $\mathrm{M}=4.78$ out of 11 points). The quality scores for each study are presented in Appendix aTable 3.

\section{Narrative synthesis of results}

In this section we present a narrative synthesis of the data on the effectiveness of MCP for all primary and secondary outcomes, reported across the seven studies included in the review ${ }^{(11-13,29-32)}$. A summary of intragroup (pre-post) data by each experimental condition is presented in Table 2 and Table 3 , and intergroup (betweengroup) data in Table 4.

\section{Primary outcomes}

\section{Spiritual well-being}

Four RCTs $(\mathrm{n}=639)$ reported data on spiritual well-being ${ }^{(11,12,31,32)}$. Intragroup comparisons ${ }^{(11,31,32)}$ showed an improvement at post-treatment $v s$ baseline for the MCP group, in a range of moderate $(\mathrm{d}=0.54$ and $\mathrm{d}=0.72)$ to large $(\mathrm{d}=0.86)$. For the control group, two studies did not report a significant improvement at post-treatment $v s$ baseline ${ }^{(11,31)}$, and a third trial reported a low $(\mathrm{d}=0.31)$ therapeutic improvement for enhanced usual care and moderate $(\mathrm{d}=0.57)$ for supportive psychotherapy ${ }^{(32)}$. At 2-month follow-up, the MCP group maintained the statistically significant improvements in a range of $\mathrm{d}=0.48$ to $\mathrm{d}=1.46^{(11,31,32)}$. There were no differences in follow-up for control conditions in two studies ${ }^{(11,31)}$, while one trial ${ }^{(32)}$ reported a low therapeutic effect for enhanced usual care $(\mathrm{d}=0.49)$ and supportive psychotherapy $(\mathrm{d}=0.48)$. Between-group data, provided by one trial ${ }^{(12)}$, indicated a superiority of MCP vs control at post-treatment $(\mathrm{d}=0.39, \mathrm{p}<0.001)$, but this difference became nonsignificant at 2 months $(\mathrm{d}=0.20, \mathrm{p}=0.2)$.

\section{Quality of life}

Three RCTs $(\mathrm{n}=584)$ reported data on $\mathrm{QoL}^{(12,31,32)}$. Intragroup comparisons indicated a low $(\mathrm{d}=0.40)$ and moderate $(\mathrm{d}=0.78)$ clinical improvement for $\mathrm{MCP}$ at posttreatment, which remined significant ( $\mathrm{d}=0.35$ and $\mathrm{d}=0.49$, respectively) at follow$u^{(31,32)}$. Control groups showed no statistically significant improvements at either post-treatment or follow-up ${ }^{(31,32)}$. Between-group data indicated a therapeutic advantage of MCP $v s$ control $(\mathrm{d}=0.76, \mathrm{p}=0.013)$, although it was not maintained at 2-month follow-up $(\mathrm{d}=0.36, \mathrm{p}=0.30)^{(12)}$. 


\section{Sense of meaning}

One $\mathrm{RCT}^{(32)}$ including $\mathrm{n}=274$ participants reported outcome data on sense of meaning. Intragroup analysis indicated a large $(\mathrm{d}=1.03)$ improvement in the MCP group at posttreatment, which decreased slightly but remained significant at follow-up $(\mathrm{d}=0.82)$. Control group 1 (supportive psychotherapy) presented a moderate improvement at post-treatment and follow-up $(\mathrm{d}=0.59$ and $\mathrm{d}=0.54$, respectively), and control group 2 (enhanced usual care) a small improvement only at follow-up $(\mathrm{d}=0.29)^{(32)}$.

\section{Secondary outcomes}

\section{Anxiety}

Five RCT $(\mathrm{n}=686)$ reported outcome data on anxiety ${ }^{(11,12,30-32)}$. Intragroup analyses indicated a moderate symptomatic improvement (range of $\mathrm{d}=-0.52$ to $\mathrm{d}=-0.73$ ) in three out of four studies at post-treatment ${ }^{(30-32)}$, and a small to moderate improvement (d=-0.36 to -0.72) at 2 month of follow-up time in three out of four studies ${ }^{(11,31,32)}$. For control conditions, only supportive psychotherapy obtained a small improvement at post-treatment $(\mathrm{d}=-0.37)^{(32)}$, while at follow ap, a small to moderate therapeutic benefit was observed for enhanced usual care $(\mathrm{d}=-0.29)$ and supportive psychotherapy $(\mathrm{d}=-$ $0.57)$, respectively ${ }^{(32)}$. No between-group differences were reported at either posttreatment or follow-up in one trial ${ }^{(12)}$.

\section{Depression}

Intragroup data on the effect of MCP for depressive symptoms was reported by four studies ${ }^{(11,30-32)}$. Of these, three trials ${ }^{(30-32)}$ reported a therapeutic improvement for MCP in a moderate $(\mathrm{d}=-0.51)$ to large $(\mathrm{d}=-1.27)$ range, which remained in a small to moderate range $(\mathrm{d}=-0.46$ to $\mathrm{d}=-0.54)$ at 2 -month in two studies ${ }^{(31,32)}$. For the control conditions, only supportive group psychotherapy $(\mathrm{d}=-0.34)^{(31)}$ and supportive psychotherapy $(\mathrm{d}=-0.48)^{(32)}$ presented an improvement at the end of treatment. At follow-up, both control conditions maintained the clinical improvement $(\mathrm{d}=-0.39$ and $\mathrm{d}=-0.58$, respectively). Only one $\mathrm{RCT}(\mathrm{n}=77)$ reported between-group data, not observing a significant difference in depressive symptoms between MCP and the therapeutic massage control group ${ }^{(12)}$.

\section{Hopelessness}

Three RCTs reported intragroup data for hopelessness ${ }^{(11,31,32)}$, with two finding a moderate therapeutic improvement of $\mathrm{d}=-0.56^{(32)}$ and $\mathrm{d}=-0.53^{(31)}$, which remained significant at follow-up in a small $(\mathrm{d}=-0.46)^{(32)}$ to moderate $(\mathrm{d}=-0.55)^{(31)}$ effect. One study also reported a small improvement for the supportive psychotherapy $(\mathrm{d}=-0.33)$ and enhanced usual care $(\mathrm{d}=-0.48)$ control conditions, which remained in the same therapeutic range at follow-up ${ }^{(32)}$. No differences were reported between MCP and therapeutic massage in between-group comparisons ${ }^{(12)}$. 


\section{Demoralisation}

Only one trial ${ }^{(30)}$ of $n=51$ participants assessed demoralisation, reporting a posttreatment therapeutic improvement of $\mathrm{d}=-1.26$ for MCP, in intragroup comparisons. There was no significant improvement for the counselling control condition.

\section{Desire for hastened death}

Three RCTs reported intragroup data on desire for hastened death ${ }^{(11,31,32)}$. Two trials ${ }^{(31,32)}$ reported a small improvement for the MCP group at post-treatment $(\mathrm{d}=-$ 0.31 and $\mathrm{d}=-0.42$ ), and all three reported a small to moderate effect at follow-up $(\mathrm{d}=-0.27$ to $\mathrm{d}=-0.63$ ). There was no significant improvement for the control groups at either post treatment or follow-up.

\section{Participant satisfaction}

Participant satisfaction was assessed by three studies: one adaptation trial of MCP for palliative care settings ${ }^{(13)}$ and two RCTs of MCP-PC ${ }^{(29,30)}$. The assessment was carried out through a brief questionnaire to obtain the participants' perceptions and feedback. No patient reported feeling distressed by the content of the intervention, and they were satisfied with the programme's length ("neither too long nor too short") ${ }^{(13,29,30)}$. In the study by Rosenfeld et al. $2017^{(13)}, 50 \%$ of participants considered that MCP was either "quite a bit helpful" or "very much helpful" for enhancing their sense of meaning ( $0 \%$ reported "not at all").

\section{Quantitative synthesis: meta-analysis}

In this section we present the results of our meta-analysis for intragroup (Figure 2, Appendix aTable 4) and intergroup (Appendix aTable 5) comparisons. Four RCTs $(n=604)$ were included in the meta-analysis, covering the outcomes of spiritual well-being, QoL, anxiety, depression, desire for hastened death, and risk of abandonment ${ }^{(12,30-32)}$. Control conditions included therapeutic massage ${ }^{(12)}$, group $^{(31)}$ and individual ${ }^{(32)}$ supportive therapy, and counselling-based therapy ${ }^{(30)}$. The average quality score of included studies was $\mathrm{M}=55.57(\mathrm{SD}=9.29)$, in a rage of 43 to 65 . The remaining three trials were not included in the quantitative synthesis due to employing a non-RCT design ${ }^{(13)}$, not providing enough quantitative for the analyses ${ }^{(11)}$, or lacking data on the outcomes of interest ${ }^{(29)}$. Detailed quantitative results of the sensitivity analyses for both for intragroup and intergroup comparisons are available in the appendix (Appendix aTable 6-7, respectively).

\section{Intragroup comparisons}

In intragroup (pre-post) comparisons at post-treatment $v s$ baseline, participants exposed to MCP presented a low to moderate clinical improvement for all outcomes: spiritual well-being $(\mathrm{d}=0.52, \mathrm{p}<0.001)$, QoL $(\mathrm{d}=0.60, \mathrm{p}<0.001)$, anxiety $(\mathrm{d}=-0.47, \mathrm{p}<0.001)$, depression $(\mathrm{d}=-0.50, \mathrm{p}<0.001)$, and desire for hastened death $(\mathrm{d}=-0.28, \mathrm{p}<0.001)$. Controls presented a low therapeutic improvement only for spiritual well-being $(\mathrm{d}=0.27, \mathrm{p}=0.042)$. Anxiety $(\mathrm{d}=-0.17, \mathrm{p}=0.041)$ and $\mathrm{QoL}(\mathrm{d}=0.17, \mathrm{p}=0.010)$ were also 

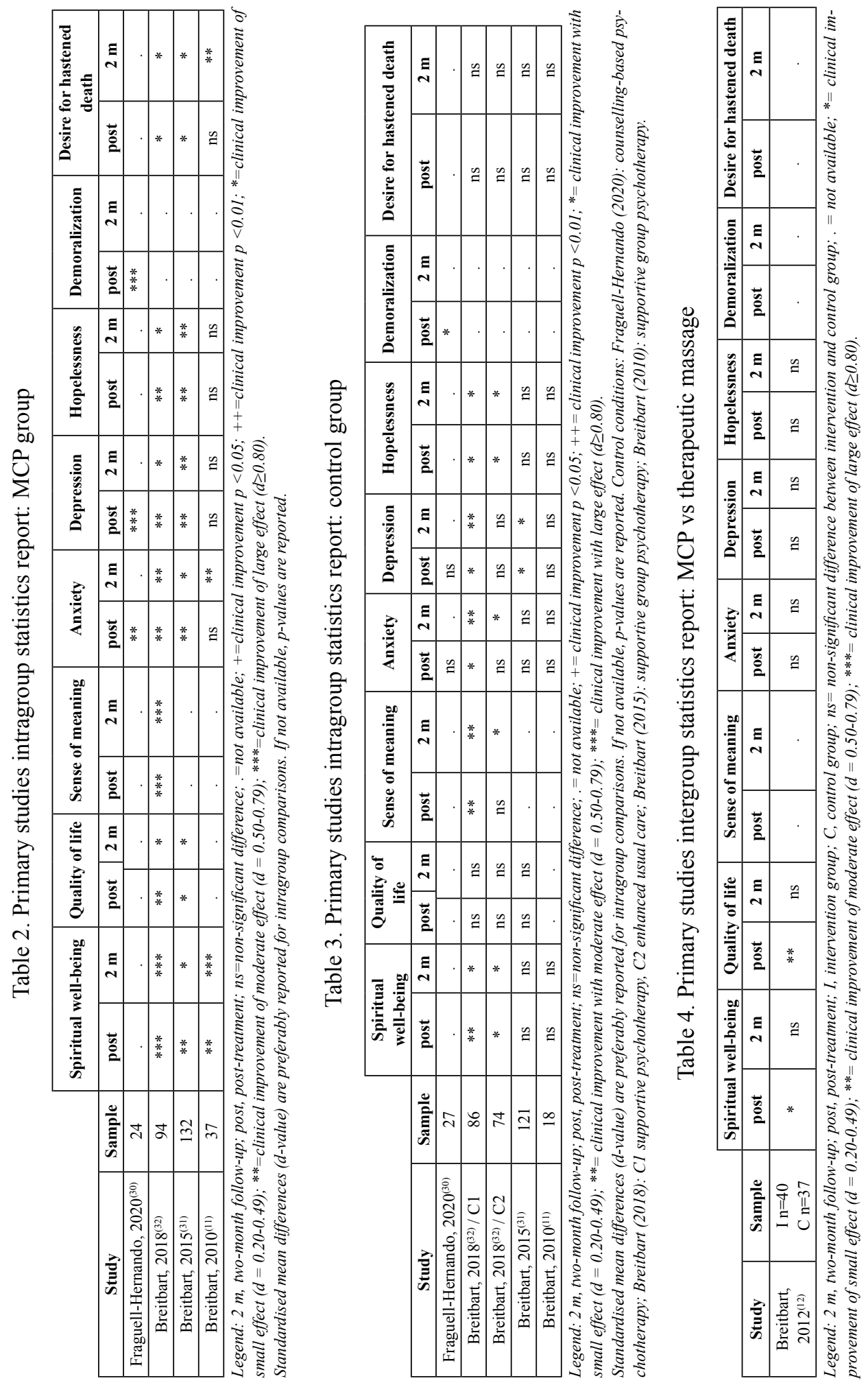
significant for controls, but the ES was below the level of clinical relevance $(\mathrm{d}<0.20)$. No significant differences were observed for depression and desire for hastened death in the control group, at post-treatment. At 2 months of follow-up, the MCP group maintained a low and significant clinical improvement across all five outcomes, while the control group did so only for the spiritual well-being $(\mathrm{d}=0.28, \mathrm{p}=0.008)$ and depression $(\mathrm{d}=-0.43, \mathrm{p}=0.001)$ outcomes (all the rest remained non-significant).

As indicated by the summary of intragroup ES and $95 \%$ confidence intervals in Figure 2, the MCP condition presented a superior clinical improvement than controls across all five outcomes, and in all time points (post-treatment and follow-up).

In sensitivity analyses using the 'one study removed' function, the MCP group maintained the significant differences against baseline levels for both primary outcomes (spiritual well-being and QoL) at both assessment times. On the contrary, the spiritual well-being and QoL ESs for the control group are no longer significant, at both time points, when removing one or two of the included trials.

Figure 2. Forest plot for intragroup differences

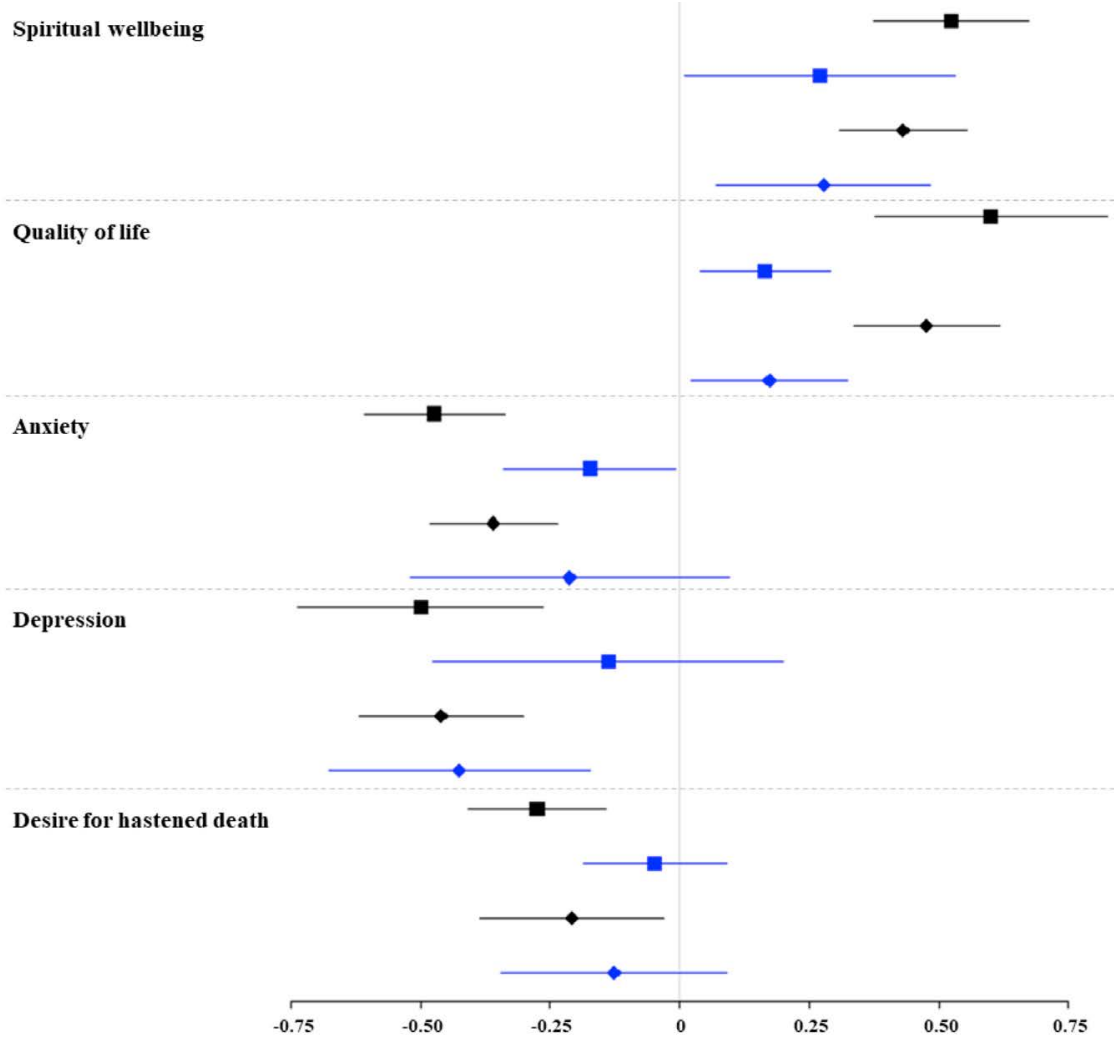

MCP: baseline vs post-treatment Control: baseline vs post-treatment MCP: baseline vs 2-month follow-up Control: baseline vs 2-month follow-up

Legend: MCP, Meaning-Centred Psychotherapy. Displayed values represent standardised mean differences (SMD) and 95\% confidence intervals. For spiritual well-being and quality of life, $S M D>0$ indicate a therapeutic improvement; for anxiety, depression and desire for hastened death, $S M D<0$ indicate a therapeutic improvement 


\section{Intergroup comparisons}

The meta-analysis yielded no statistically significant differences between the MCP $v s$ the control groups for any of the included outcomes (anxiety, depression, QoL, spiritual well-being and desire for hastened death) at any of the three time points: baseline, post-treatment, and 2-month follow-up. The $\mathrm{I}^{2}$ statistic indicated moderate to high levels of between-study heterogeneity at post-treatment for anxiety $\left(\mathrm{I}^{2}=78 \%\right)$, depression $\left(\mathrm{I}^{2}=81 \%\right)$, and QoL $\left(\mathrm{I}^{2}=67 \%\right)$; and at 2-month follow-up for anxiety $\left(\mathrm{I}^{2}=59 \%\right)$. In addition, MCP was not associated with an increased risk of abandonment at post-treatment, when compared to control conditions ( $\mathrm{OR}=0.86$, $\mathrm{p}=0.57)$.

Sensitivity analyses using the 'one study removed' function indicated statistically significant differences $(\mathrm{p}<0.005)$ at baseline (pre-treatment) for spiritual well-being and QoL when removing the trial by Breitbart et al. (2018) ${ }^{(32)}$, and at post-treatment for QoL when removing the trial by Breitbart et al. (2015) ${ }^{(31)}$.

\section{Discussion}

To the best of our knowledge, this is the first systematic review and meta-analysis to specifically assess the effectiveness of manualized MCP interventions for adult advanced cancer patients. The clinical evidence synthetized in this review supports the effectiveness of MCP as an intervention to address the spiritual needs and psychological distress of patients. This is reflected by the clinical improvements observed across a set of primary outcomes (spiritual well-being, quality of life and sense of meaning) in participants exposed to different variants of manualized MCP interventions (MCGP, IMCP, MCP-PC).

Clinical trials report consistent results regarding primary outcomes. Regarding spiritual well-being, the intragroup analyses reported a moderate to large therapeutic effect on post-treatment and a small to large effect on the follow-up for $\operatorname{MCP}^{(11,31,32)}$. This was superior to the effect observed across control conditions. MCP was also superior to controls for QoL ${ }^{(12,31,32)}$, with a clinical improvement at both posttreatment and follow-up (with no effect over QoL for controls at either time point). Finally, the only study assessing sense of meaning ${ }^{(32)}$ reported a large therapeutic effect in favour of MCP at both post-treatment and follow-up vs a small to moderate improvement in controls.

At both post-treatment and 2-month follow-up, our meta-analytic synthesis for intragroup (pre-post) comparisons also indicated a low to moderate clinical improvement in spiritual well-being and QoL for participants exposed to MCP. In fact, MCP was superior to control conditions across all our intragroup estimates, as reflected by our forest plot in Figure 2. Furthermore, the MCP pre-post ESs remained significant after sensitivity analyses, unlike many of the control group estimates. It should be noted, however, that our between-group estimates did not find statistically significant differences for MCP vs control conditions. In addition, intergroup ESs were less robust. when applying the 'one study removed' test. The lack of a significant between-group difference could be reflective of the heterogeneity in control conditions across trials. Unfortunately, we were unable to conduct subgroup or meta-regression analyses to test this hypothesis. 
While less consistent and robust than for primary outcomes, evidence is also promising regarding the therapeutic utility of MCP across our selection of secondary outcomes, which included anxiety, depression, desire for hastened death, hopelessness, demoralization, and satisfaction.

Clinical evidence from three trials ${ }^{(30-32)}$ supported the utility of MCP to alleviate anxiety and depressive symptoms at post-treatment and follow-up, resulting in a small to large therapeutic effect. Our intragroup meta-analytic synthesis indicated a significant improvement in the MCP condition that was maintained at follow-up and was superior to the estimates for the control group.

MCP was also superior to control conditions in the reduction of the desire for hastened death. A low therapeutic effect at post-treatment was reported for MCP by two trials ${ }^{(31,32)}$, and a low to moderate effect at follow-up by three trials ${ }^{(11,31,32)}$. These results were corroborated in our pre-post meta-analytical estimates.

Evidence regarding hopelessness is less consistent. Only two ${ }^{(31,32)}$ of the three trials with intragroup data on this outcome report a moderate clinical improvement in the MCP group, which is maintained at follow-up in a small to moderate effect. In the remaining study, no improvement either at post-treatment or follow-up was reported $^{(11)}$. Finally, only one trial of $n=51$ participants ${ }^{(30)}$ assessed the impact of MCP on demoralization, reporting a high clinical improvement $(\mathrm{d}=-1.26)$ at the end of treatment, in intragroup analyses. There were not enough studies available to conduct meta-analyses for the hopelessness and demoralization outcomes.

Finally, MCP interventions seem to be well-received by patients, as reflected by the high levels of participant satisfaction with the interventions' length, format, and content across three distinct trials ${ }^{(13,29,30)}$. In support of this, our meta-analytical estimates did not find a significant difference in risk of abandonment between MCP and control conditions $(\mathrm{OR}=0.86, \mathrm{p}=0.57)$.

\section{Limitations of the clinical evidence}

While our results support the efficacy of MCP across a selection of existential and clinical outcomes, they should be interpreted taking into consideration the limitations of the available evidence. As such, we believe our conclusions should be considered as preliminary, and subject to future revisions as new clinical trials of MCP for adult cancer patients are published.

The clinical evidence is still in an emerging state, as reflected by the limited number of individual trials. In total, seven studies met our inclusion criteria $(71 \%$ being classified as "pilot" studies by their authors), reporting data on $n=830$ participants. Likewise, our meta-analytic estimates included an average of $\mathrm{M}=367$ ( $\mathrm{SD}=94.31$ ) participants for between-group analyses, and $\mathrm{M}=210(\mathrm{SD}=20,28)$ for intragroup (prepost) analyses. The limited number of participants increased the margin of error of the meta-analytic estimates, as reflected by the broad confidence intervals.

We also identified a series of methodological shortcomings among MCP trials that should be addressed in future studies. For instance, most RCTs are lacking a clear description of the randomization method, and thus the presence of a selection bias cannot be discarded. Furthermore, scores were often low for the assessment domain in the CTAM (i.e. use of independent evaluators, blinding of evaluators, and clear description of the assessment process), which could increase the risk of detection bias. 


\section{Limitations of our meta-analysis and systematic review}

The limitations of our review and meta-analysis reflect the emerging nature of the clinical evidence on MCP. As such, the limited number of clinical trials prevented subgroup analyses to be conducted to explore potential causes for between-study heterogeneity. This is relevant given that heterogeneity was moderate to high $\left(\mathrm{I}^{2} \geq 50 \%\right)$ in $44 \%$ of the between-study and $40 \%$ of pre-post ESs. Trials differed in the type of MCP intervention, control condition, and number of sessions. Similarly, meta-regression and publication bias analyses were discarded as the minimum recommended number studies $(\mathrm{k}=10)$ could not be reached ${ }^{(33)}$. As a result, it is still unclear to what extent the different manualized programmes of MCP differ in term of their effectiveness and acceptability, nor how they compare head-to-head against other active control conditions.

In addition, we used a generic pre-post correlation value of 0.59 for our intragroup meta-analyses, as this data was not reported by the individual trials. However, this value is evidence-based ${ }^{(24)}$, and represents a more conservative value then the 0.75 frequently used in pre-post analyses ${ }^{(34)}$. Finally, our search and study selection process was restricted to English and Spanish language. This could have potentially neglected relevant clinical trials published in other languages.

\section{Strengths of our meta-analysis and systematic review}

Our study selection expands on the number of MCP clinical trials of previous metaanalyses ${ }^{(19-21)}$, by incorporating four new reports published since $2017^{(13,29,30,32)}$ and $\mathrm{n}=346$ participants.

In addition, only RCTs were considered for our meta-analytical synthesis, unlike previous reports that combined randomised and nonrandomised trials ${ }^{(21)}$. Among the different clinical trial designs, RCTs have a lower risk of bias and are more effective at controlling confounding variables. As a result, RCTs are considered of higher methodological quality than nonrandomised trials ${ }^{(35)}$.

Similarly, only manualized MCP interventions were included in our review and meta-analysis. This decision was taken to reduce between-study heterogeneity and increase the accuracy of estimates, and differs from previous meta-analyses that combined MCP alongside other existentially-oriented interventions ${ }^{(19-21)}$.

Finally, our meta-analysis only included low-intensity active control conditions, which are more effective than nonactive conditions (e.g. waitlist) for controlling the therapeutic effect of nonspecific variables ${ }^{(33)}$. As a recent umbrella review has reported $^{(36)}$, the effectiveness of psychotherapeutic interventions often decreases, at times becoming nonsignificant, when comparing them against control conditions with an active component.

\section{Conclusion}

The clinical evidence reviewed and synthetized in our study suggests that manualized MCP interventions have the potential to enhance the sense of meaning and improve the spiritual well-being and QoL of adult patients with advanced cancer. In addition, MCP intervention could reduce the psychological distress 
associated with facing a life-threatening illness. The evidence base is still in an emerging state, and these findings should be replicated in the future by higher methodological quality studies.

\section{References}

1. Vehling S, Koch U, Ladehoff N, Schön G, Wegscheider K, Heckl U, et al. Prevalence of affective and anxiety disorders in cancer: Systematic literature review and meta-analysis. Psychother Psych Med 2012;62:249-58. https://doi.org/10.1055/s-0032-1309032

2. Mehnert A, Vehling S, Höcker A, Lehmann C, Koch U. Demoralization and depression in patients with advanced cancer: Validation of the German version of the demoralization scale. J Pain Symptom Manage 2011;42:768-76. https://doi.org/10.1016/j. jpainsymman.2011.02.013

3. Kissane DW, Clarke DM, Street AF. Demoralization syndrome - A relevant psychiatric diagnosis for palliative care. J Palliat Care 2001;17:12-21. https://doi. org/10.1177/082585970101700103

4. Breitbart W, Rosenfeld B, Pessin H, Kaim M, Funesti-esch J, Galietta M, et al. Desire for hastened death in terminally ill patients with cancer. JAMA 2000;284:2907-11. https:// doi.org/10.1001/jama.284.22.2907

5. Robinson S, Kissane DW, Brooker J, Burney S. A systematic review of the demoralization syndrome in individuals with progressive disease and cancer: A decade of research. J Pain Symptom Manage 2015;49:595-610. https://doi.org/10.1016/j.jpainsymman.2014.07.008

6. Julião M, Sobral MA, Calçada P, Antunes B, Runa D, Samorinha C, et al. The desire for death in Portuguese home-care palliative patients: Retrospective analysis of the prevalence and associated factors. Palliat Support Care 2021;19:457-63. https://doi. org/10.1017/S1478951520000863

7. Kissane DW, Bloch S, Miach P, Smith GC, Seddon A, Keks N. Cognitiveexistential group therapy for patients with primary breast cancer - Techniques and themes. Psychooncology 1997;6:25-33. https://doi.org/10.1002/(SICI)10991611(199703)6:1<25::AID-PON240>3.0.CO;2-N

8. Breitbart W, editor. Meaning-centered psychotherapy in the cancer setting. Finding meaning and hope in the face of suffering. New York: Oxford University Press, 2017.

9. Greenstein M, Breitbart W. Cancer and the experience of meaning: A group psychotherapy program for people with cancer. Am J Psychother 2000;54:486-500. https://doi. org/10.1176/appi.psychotherapy.2000.54.4.486

10. Frankl V. El hombre en busca de sentido. El hombre en busca de sentido (nueva traducción). Barcelona: Editorial Herder, 2019.

11. Breitbart W, Rosenfeld B, Gibson C, Pessin H, Poppito S, Nelson C, et al. Meaningcentered group psychotherapy for patients with advanced cancer: A pilot randomized controlled trial. Psychooncology 2010;19:21-8. https://doi.org/10.1002/pon.1556

12. Breitbart W, Poppito S, Rosenfeld B, Vickers AJ, Li Y, Abbey J, et al. Pilot randomized controlled trial of individual meaning-centered psychotherapy for patients with advanced cancer. J Clin Oncol 2012; 30:1304-9. https://doi.org/10.1200/JCO.2011.36.2517

13. Rosenfeld B, Saracino R, Tobias K, Masterson M, Pessin H, Applebaum A, et al. Adapting Meaning-Centered Psychotherapy for the palliative care setting: Results of a pilot study. Palliat Med 2017;31:140-6. https://doi.org/10.1177/0269216316651570 
14. Lichtenthal W, Napolitano S, Roberts K, Sweeney C, Slivjak E. Meaning-Centered Grief Therapy. In: Breitbart W, editor. Meaning-Centered Psychotherapy in the cancer setting finding meaning and hope in the face of suffering. Oxford University Press, 2017. p. 88-99.

15. Lichtenthal W, Roberts K, Jankauskaite G, Craig C, Wiatrek D, Sharpe K, et al. MeaningCentered Group Psychotherapy for breast cancer survivors. In: Breitbart W, editor. Meaning-Centered Psychotherapy in the cancer setting Finding meaning and hope in the face of suffering. Oxford University Press, 2017. p. 54-66.

16. Applebaum A. Meaning-Centered Psychotherapy for Cancer Caregivers. In: Breitbart W, editor. Meaning-Centered Psychotherapy in the cancer setting finding meaning and hope in the face of suffering. Oxford University Press, 2017.

17. Van Der Spek N, Vos J, Van Uden-Kraan CF, Breitbart W, Cuijpers P, Holtmaat K, et al. Efficacy of Meaning-Centered group Psychotherapy for cancer survivors: A randomized controlled trial. Psychol Med 2017;47:1990-2001. https://doi.org/10.1017/ S0033291717000447

18. Kearney J, Ford J. Meaning-Centered Psychotherapy for adolescents and young adults with cancer: Issues of meaning and identity. In: Breitbart W, editor. Meaning-centered psychotherapy in the cancer setting finding meaning and hope in the face of suffering. Oxford University Press, 2017. p. 100-11.

19. Vos J, Craig M, Cooper M. Existential therapies: A meta-analysis of their effects on psychological outcomes. J Consult Clin Psychol 2015;83:115-28. https://doi.org/10.1037/ a0037167

20. Vos J, Vitali Di. The effects of psychological meaning-centered therapies on quality of life and psychological stress: A metaanalysis. Palliat Support Care 2018;16:608-32. https:// doi.org/10.1017/S1478951517000931

21. Kang KA, Han SJ, Lim YS, Kim SJ. Meaning-centered interventions for patients with advanced or terminal cancer: A meta-analysis. Cancer Nurs 2019;42:332-40. https://doi. org/10.1097/NCC.0000000000000628

22. Moher D, Liberati A, Tetzlaff J, Altman DG. Preferred reporting items for systematic reviews and meta-analyses: The PRISMA Statement. PLoS Med. 2009;6. https://doi. org/10.1136/bmj.b2535

23. Cohen J. Statistical Power Analysis for the Behavioral Sciences. Associates LE, editor. New York, 1988.

24. Balk E, Earley A, Patel K. Empirical assessment of within-arm correlation imputation in trials of continuous outcomes. Agency Healthc Res Qual [Internet]. 2012;12. Available from: http://www.ncbi.nlm.nih.gov/pubmed/23326900

25. Higgins JPT, Thompson SG, Deeks JJ, Altman DG. Measuring inconsistency in metaanalyses. BMJ Br Med J 2003;327:557-60. https://doi.org/10.1136/bmj.327.7414.557

26. Higgins JPT GS. Manual Cochrane de revisiones sistemáticas de intervenciones. 2011; (March):1-639. Available from: www.cochrane-handbook.org.

27. DerSimonian R, Laird N. Meta-analysis in clinical trials. Control Clin Trials 1986;7:17788. https://doi.org/10.1016/0197-2456(86)90046-2

28. Tarrier $\mathrm{N}$, Wykes $\mathrm{T}$. Is there evidence that cognitive behaviour therapy is an effective treatment for schizophrenia? a cautious or cautionary tale? Behav Res Ther. 2004;42:1377401. https://doi.org/10.1016/j.brat.2004.06.020

29. Gil F, Fraguell C, Benito L, Casellas-Grau A, Limonero JT. Meaning-centered psychotherapy integrated with elements of compassion: A pilot study to assess feasibility and utility. Palliat Support Care 2018;16:643-7. https://doi.org/10.1017/ S1478951518000548 
30. Fraguell-Hernando C, Limonero JT, Gil F. Psychological intervention in patients with advanced cancer at home through Individual Meaning-Centered Psychotherapy-Palliative Care: a pilot study. Support Care Cancer 2020;28:4803-11. https://doi.org/10.1007/ s00520-020-05322-2

31. Breitbart W, Rosenfeld B, Pessin H, Applebaum A, Kulikowski J, Lichtenthal WG. Meaning-Centered group Psychotherapy: An effective intervention for improving psychological well-being in patients with advanced cancer. J Clin Oncol 2015;33:74954. https://doi.org/10.1200/JCO.2014.57.2198

32. Breitbart W, Pessin H, Rosenfeld B, Applebaum AJ, Lichtenthal WG, Li Y, et al. Individual meaning-centered psychotherapy for the treatment of psychological and existential distress: A randomized controlled trial in patients with advanced cancer. Cancer 2018;124:3231-9. https://doi.org/10.1002/cncr.31539

33. Borenstein M, Hedges L, Higgins J, Rothstein H. Introduction to Meta-Analysis. 2009.

34. Cuijpers P, Weitz E, Cristea IA, Twisk J. Pre-post effect sizes should be avoided in meta-analyses. Epidemiol Psychiatr Sci 2017;26:364-8. https://doi.org/10.1017/ S2045796016000809

35. Schmidt WP. Randomised and non-randomised studies to estimate the effect of communitylevel public health interventions: Definitions and methodological considerations. Emerg Themes Epidemiol 2017;14:1-11. https://doi.org/10.1186/s12982-017-0063-5

36. Correll CU, Cortese S, Croatto G, Monaco F, Krinitski D, Arrondo G, et al. Efficacy and acceptability of pharmacological, psychosocial, and brain stimulation interventions in children and adolescents with mental disorders: An umbrella review. World Psychiatry 2021;20:244-75. https://doi.org/10.1002/wps.20881. 